\title{
EDITORIAL
}

\section{Man's Place on Earth}

Although in many ways 'merely an animal', Man is unique in his possession of a brain that is sufficiently developed to enable him to store ever-increasing amounts of information and to transmit them to others of his kind. Moreover, Man can now effect this transmission of knowledge simultaneously throughout the world and into space. He also has intellectual consciousness, powers of reasoning, and fantastic inquisitiveness that has led to an ever-increasing tempo of scientific discovery especially in recent years, so that he now has the knowledge and means of controlling his own destiny and that of much else on Earth. Thus whereas he used to fear wild animals and wild places, Man now has Nature widely at bay, and has in fact become the currently undisputed superdominant of the world.

This surely imposes on Man the moral obligation of benevolent leadership-benevolent not only to his conspecific fellows but also to other living creatures on Earth, whether plant, animal, or whatever. Yet this benevolent leadership is often lacking even where his own fellows are concerned; and when we consider other living creatures, it is virtually nonexistent except in cases where they are directly useful to omnipotent Man. The other inhabitants of the biosphere get precious little consideration from the superdominant, and this may well turn out to be his own undoing in the long run. For these other creatures are essential to Man's own wellbeing and very life-in numerous ways which will be so familiar to most readers of these columns that it would be superfiuous to give details.

Suffice it to say that, for the ecosystem stability which is a leading feature of life on Earth, forest and other major vegetational formations have to be maintained in their age-old dynamic essentials. Yet the present disturbance by Man has already gone too dangerously far on the global scene and is still allowed to continue apace; indeed it seems to be increasing exponentially. Towards remedying this courting of disaster the United Nations Environment Programme should do far more than hold a watching brief, and indeed appears destined to do so, though the continuing virtual freefor-all in the oceans gives further cause for grave concern. It seems that Man's greed in seeking profit remains unabated despite dire warnings, and regardless of creed or ethical or other beliefs. Effective environmental leadership needs to be based on research and enlightening experience, and this the United States and some other nations and factions appear to be affording in increasing degree. We should support and reinforce these efforts in every possible way, sinking our differences for the global good, and passing on our gospel with such persuasive force that political action in the right direction becomes the order of each passing day and decade. For it is the sine qua non if mankind and the biosphere are to survive in any equitable form.

Meanwhiles Man is disturbing the biosphere in ways and to degrees that cannot be supported indefinitely, and that tend to increase alarmingly with his ever-increasing numbers and profligate use of often irreplaceable raw materials. Probably the most devastating failure of modern Man is to control his own numbers, though he now has the knowledge and means to do so. The result is that human population pressures impose increasingly on the biosphere the greatest threats to which it has ever been subjected. Such population-swarming can only have an inevitable outcome of disaster, though what form of a crash will come can only be a matter for conjecture.

It is paradoxical that so many-probably the vast majority_-of activities undertaken by Man in the name or anyway guise of humanity should be contrary to ecological 'interests' and hence environmentally undesirable or worse. Thus, as pointed out by our perceptive Editorial Assistant, we have a chronic confrontation of humanity versus ecology. The very prolongation of human life, increasing population pressures and the use of raw materials, is a gentle case in point; a potentially far more violent one is the widespread development of nuclear fission energy, which has grave dangers in the manners already indicated in these columns. Yet Man has somehow to solve his energy problems. How he does so must be watched and should be guided inter alia by qualified environmentalists, who should pervade industry and government at least at managerial level. Above all is international agreement and concomitant action needed, and to that end the United Nations seem to be our main hope.

Although attempts are being made in an increasing number of countries to control human population by peaceful means of contraception and better education, it seems unlikely that these will be effective in time on a sufficient scale to save the world from widespread disaster. Apart from the all-too-evident possibilities of nuclear holocaust, perhaps followed by uncontrollable pandemics ravaging a weakened world, widespread famine would seem the most likely means for Nature to control human population, though there are some who expect people in time to kill one another in sufficient numbers to take care of the situation. Meanwhile, life on Earth is changing inexorably-not only for human beings but also for other living creatures. Many of these are faced with extermination or drastic curtailment of their areas and populations-to an extent which not only affects Man's 'quality of life' (almost whatever that commonly-used phrase may be taken to mean!) but could also jeopardize his very existence.

This brings us back to the question of morality pointing to Man's proper place on Earth. Should his objective not be to maintain optimum diversity (to use the phrase of a wise friend) in the biosphere? Man alone among living creatures has the knowledge and means to do this, though what the optimum should be is a matter for debate in which we will not attempt to impose our thoughts here at this stage. Unfortunately for his own health and sanity (now often in jeopardy because of the lack of it), a high degree of environmental diversity is essential for Man himself-even as it is for the continued existence of most other living beings. They, too, have a right to live on the limited confines of planet Earth-which is the crux of our none-too-popular argument. 